\title{
Heterotopic ossifications after arthroscopic management of femoroacetabular impingement: the role of NSAID prophylaxis
}

\author{
Filippo Randelli • Luca Pierannunzii • \\ Lorenzo Banci • Vincenza Ragone • \\ Alberto Aliprandi • Robert Buly
}

Received: 18 May 2010/ Accepted: 8 November 2010/Published online: 30 November 2010

(c) The Author(s) 2010. This article is published with open access at Springerlink.com

\begin{abstract}
Background Open hip surgery is known to be a risk for heterotopic ossification (HO), and nonsteroidal antiinflammatory drugs (NSAIDs) have been widely recognized as an effective prevention. Hip arthroscopy is gaining popularity thanks to the possibility of treating femoroacetabular impingement (FAI) with a minimally invasive technique, however little is known about its rate of postoperative HO. The aim of the present study is to evaluate HO prevalence after hip arthroscopy for FAI and its relationship with NSAID prophylaxis.

Materials and methods We retrospectively reviewed 300 FAI cases who have been managed with hip arthroscopy in two different hospitals from April 2006 to May 2009. All medical records and indications at discharge were analyzed, focusing on administration of NSAIDs, as well as follow-up roentgenograms with regard to presence of $\mathrm{HO}$ around the hip joint. The patients were divided into two groups: a treatment group of 285 hips which received NSAID prophylaxis and a control group of 15 hips which did not.

Results Five hips presented $\mathrm{HO}$, with overall prevalence of $1.6 \%$. All five patients with $\mathrm{HO}$ belonged to the control

\author{
F. Randelli · L. Banci $(\bowtie) \cdot$ V. Ragone $\cdot$ A. Aliprandi \\ Policlinico San Donato, P.zza Malan, 2, \\ 20097 San Donato Milanese, Milan, Italy \\ e-mail: lorenzo.banci@tiscali.it \\ L. Pierannunzii \\ Istituto Ortopedico Gaetano Pini, P.zza Cardinal Ferrari, \\ 1, 20122 Milan, Italy \\ R. Buly \\ Hospital for Special Surgery, New York, NY, USA
}

group. No HO was observed in the treatment group. Thus, HO rate turned out to be significantly higher $(P<0.001)$ in patients who did not receive NSAIDs after surgery.

Conclusion Arthroscopic treatment of FAI is not exempt from potential development of HO. NSAIDs after arthroscopic FAI treatment seem to be an effective prevention.

Keywords Hip arthroscopy · Femoroacetabular impingement · Heterotopic ossification · NSAIDs

\section{Introduction}

Heterotopic ossification ( $\mathrm{HO}$ ) or ectopic bone formation is the formation of bone in soft tissue where bone normally does not exist. HO is a well-known complication after open hip surgery such as total hip replacement, open reduction and internal fixation of hip and pelvic fractures, and jointsparing reconstructive surgery (i.e., surgical dislocation) [1]. An increasing number of reports have been presented since the 1970s [2, 3]. In previous reports, prevalence of ectopic ossification after total hip replacement (THR) varied widely between 5\% [4] and 90\% [5].

Nonsteroidal anti-inflammatory drugs (NSAIDs), conventional cyclooxygenase (COX) inhibitors, and, most recently, selective $\mathrm{COX}-2$ inhibitors (COXIB), have been shown to be effective in lowering incidence of $\mathrm{HO}$ after total hip replacement [6-9].

However, although much has been reported and described in literature about ectopic bone formation after open hip surgery, little is known and documented about this complication after hip arthroscopy. This procedure has recently gained popularity thanks to the possibility of managing femoroacetabular impingement (FAI) [10-13]. 
Despite several case reports of HO after arthroscopic surgeries in different joints [14-17], HO development after hip arthroscopy has not been deeply investigated so far. Only one recent study reported $\mathrm{HO}$ as one of the possible complications following hip arthroscopy [18].

The aim of the present retrospective study is to report the HO rate from a consecutive series of patients who underwent hip arthroscopy for FAI, and to evaluate its association with NSAID prophylaxis. The hypothesis is that the risk of developing $\mathrm{HO}$ is higher if NSAID prophylaxis is not administered.

\section{Materials and methods}

All hip arthroscopies performed for FAI correction in two different hospitals between April 2006 and May 2009 were included. Cases whose medical records were not completely available were ruled out of the study, as were all cases that had follow-up shorter than 6 months. Three hundred hips, in 300 patients, could be included: 51 procedures were performed in hospital A; the remaining 249 procedures were performed in hospital B. All patients gave informed consent prior to being included in the study. The study was authorized by the local ethical committee and was performed in accordance with the ethical standards of the 1964 Declaration of Helsinki as revised in 2000.

The study population was composed of 180 males and 120 females, with mean age of 37.4 years (range 16-66 years). Average follow-up was 17.9 months (range 6 months -3 years).

All cases were operated by senior surgeons experienced in hip arthroscopy. Anteroposterior (AP) radiographs and cross-table or Dunn view were obtained preoperatively in all patients. These images were evaluated to rule out any pre-existing calcium deposits around the joint. Two or three standard arthroscopic portals were always employed: a paratrochanteric anterolateral portal, an anterior or midanterior portal, and rarely a distal accessory anterolateral portal. Routinely the anterolateral portal was established first with the aid of a C-arm image intensifier. The (mid-) anterior portal was subsequently performed in an out-in fashion under direct visualization. Traction was used to access the central compartment. Capsulotomy was always performed, while true capsulectomy rarely occurred. Patient position was supine in hospital A, and lateral in hospital B, but procedures did not differ significantly.

All medical records were reviewed from hospital computer databases; age, gender, weight, diagnosis, date of surgery, operative report, and prescriptions at discharge were recorded. A full description of NSAID prophylaxis, if any, was recorded (drug, dose and duration). All patients whose compliance with NSAID regimen was not clearly recorded in follow-up reports were contacted by telephone to ascertain it.

Follow-up radiographs were evaluated with regard to presence of ectopic bone formation around the hip joint. Any HO was classified according to Brooker grading system [19].

We defined the treatment group as patients who received NSAID prophylaxis on a regular basis for at least 7 days, starting within $24 \mathrm{~h}$ after surgery, and the control group as patients who did not. Heterotopic ossifications rates and 95\% confidence interval (CI) were calculated for all the arthroscopies and separately for treatment and control groups. Treatment and control groups were compared according to the main independent variables and the main predisposing factors for HO formation using Fisher's exact test and independentsamples $t$ test to assess their comparability. Significance of associations between $\mathrm{HO}$ complication and pharmacological prophylaxis was assessed using Fisher's exact test. $P$-value $<0.05$ was considered statistically significant for all analyses. Statistical computations were performed using SPSS release 10.0 (SPSS Inc., Chicago, IL, USA) for Windows.

\section{Results}

Fifteen of the 300 reviewed patients received no NSAID prophylaxis nor other medications against heterotopic bone formation (control group), because of allergy towards multiple NSAIDs or because of lack of compliance. The remaining 285 patients received NSAIDs after surgery (treatment group): 15 patients received COX-2-selective NSAIDs (etoricoxib $90 \mathrm{mg}$ ) once a day for 3 weeks, and 270 patients received nonselective NSAIDs (248 patients with naproxen $500 \mathrm{mg}$ twice a day for 3 weeks, and the other 22 patients with other NSAIDs such as aceclofenac, indomethacin or ketoprofen for 3 weeks).

Of 300 hips, 5 cases ( 4 males, 1 female) presented HO after hip arthroscopy, with overall prevalence of $1.6 \%$ (95\% CI $0.2-3.0 \%$ ). All HO cases are summarized in Table 1. Treatment and control groups resulted comparable regarding the main independent variables and the main predisposing factors for $\mathrm{HO}$ formation (Table 2).

All five patients (Figs. 1, 2, 3, 4) with HO belonged to the control group, with prevalence of $33 \%(95 \% \mathrm{CI}$ $8-54 \%)$. No HO was observed within the treatment group. HO occurred in a significantly higher percentage $(P<0.001)$ in patients who did not receive any prophylaxis compared with patients who received NSAIDs.

\section{Discussion}

There are several case reports in the literature describing HO complication after different joint arthroscopic 


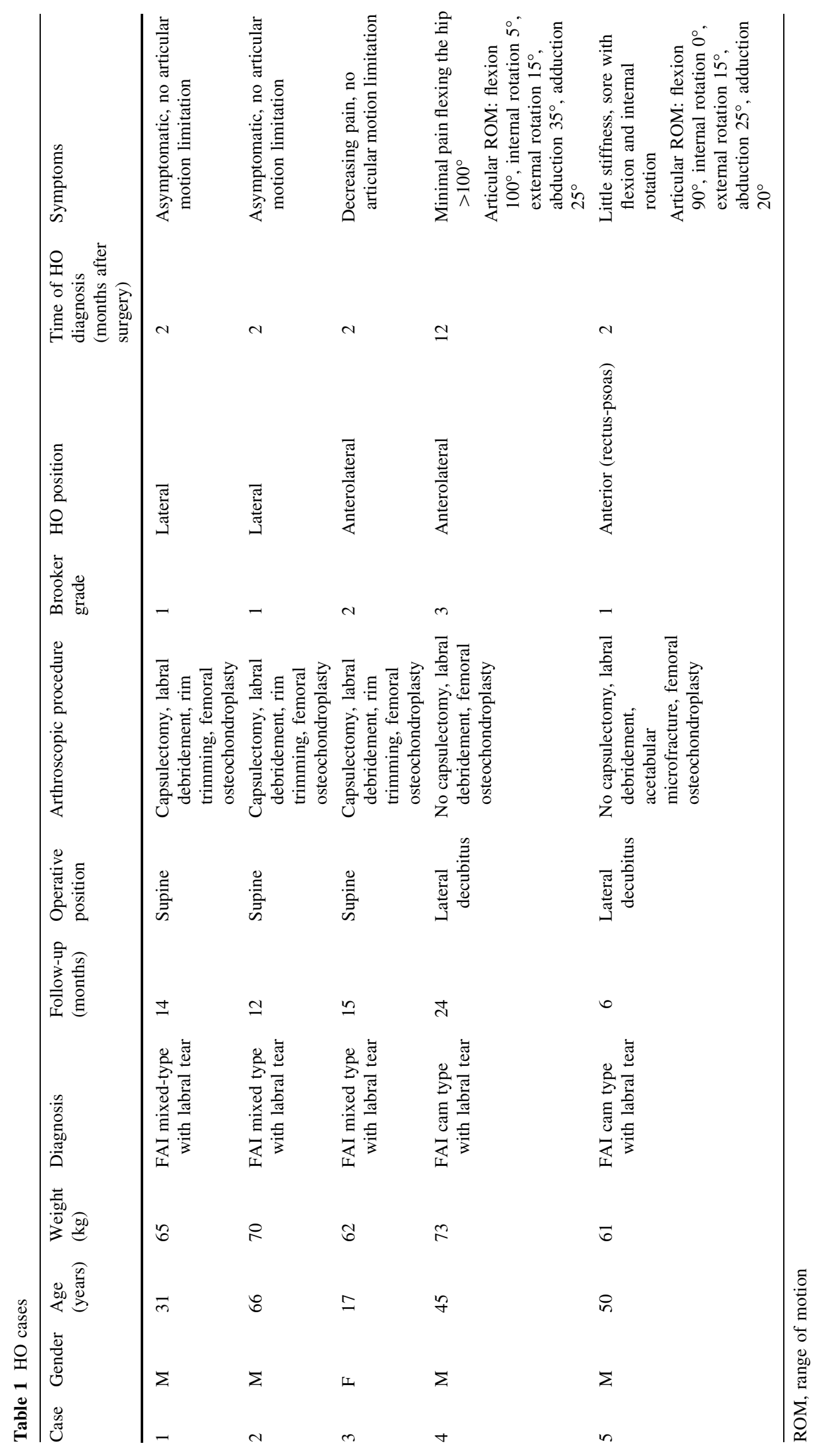


Table 2 Comparison between treatment group (postoperative NSAID prophylaxis) and control group (no postoperative NSAID prophylaxis) regarding the main independent variables and the predisposing factors for $\mathrm{HO}$ formation

\begin{tabular}{llll}
\hline & Treatment group $(n=285)$ & Control group $(n=15)$ & $P$ value \\
\hline Male & $171(60 \%)$ & $9(60 \%)$ & 0.50 \\
Age, mean \pm SD (years) & $38.1 \pm 13.2$ & $37.1 \pm 12.4$ & 0.79 \\
Weight, mean \pm SD (kg) & $71.0 \pm 12.7$ & $71.4 \pm 10.2$ & 0.91 \\
Anterolateral capsulectomy & $172(60 \%)$ & $10(67 \%)$ & 0.75 \\
Rim trimming & $122(43 \%)$ & $5(33 \%)$ & 0.41 \\
Head-neck junction osteoplasty & $179(63 \%)$ & $12(80 \%)$ & 0.054 \\
\hline
\end{tabular}

$\mathrm{SD}$, standard deviation

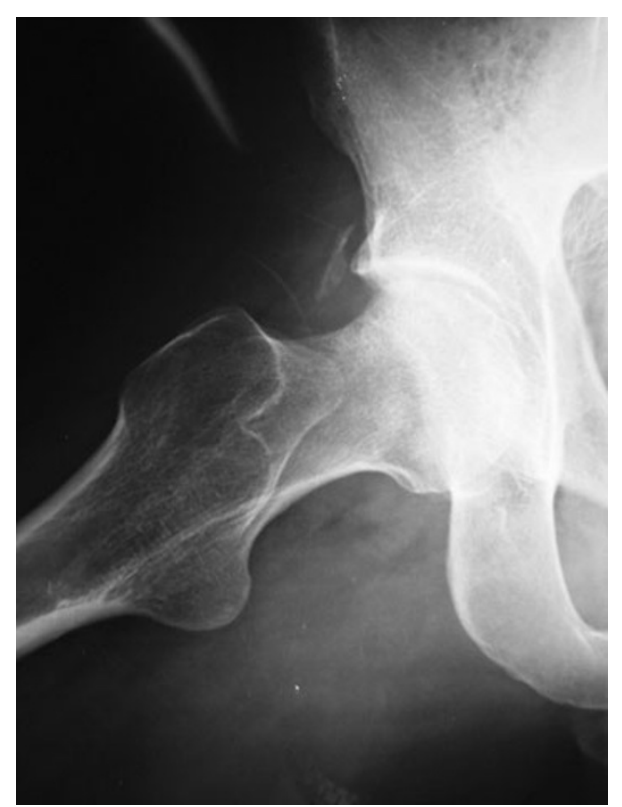

Fig. 1 Case 1: detail of axial radiograph showing grade $1 \mathrm{HO}$ at 2 months after surgery

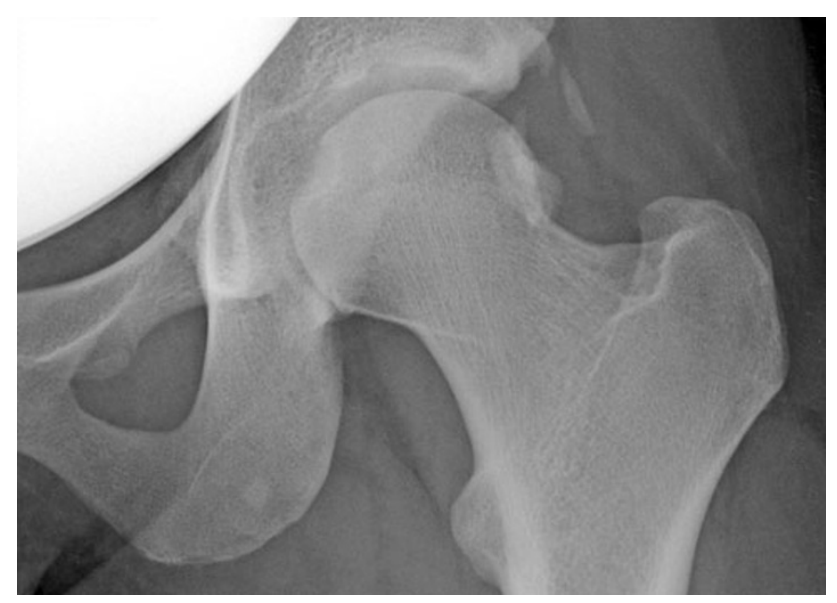

Fig. 2 Case 3: detail of anteroposterior radiograph showing grade 2 $\mathrm{HO}$ at 1 year after surgery

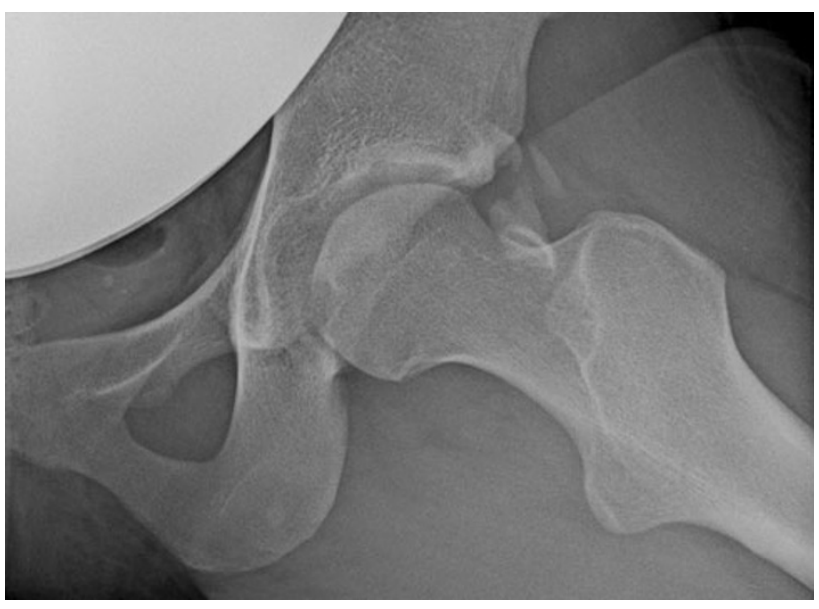

Fig. 3 Case 3: detail of axial radiograph at 1-year follow-up

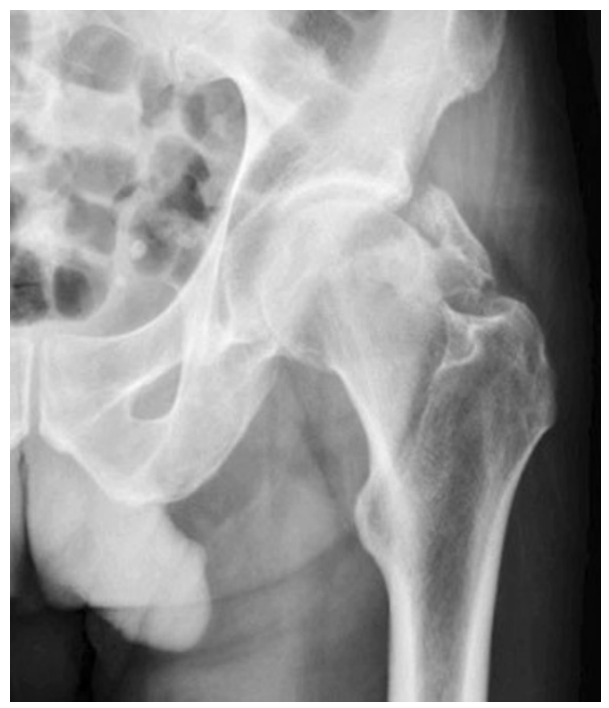

Fig. 4 Case 4: detail of anteroposterior radiograph showing grade 3 anterolateral HO 1 year after arthroscopic treatment

procedures [14-17]. A common element in these reports is the absence of any prophylactic administration of NSAIDs or other medications against ectopic bone formation. In 
fact, HO prophylaxis is not routinely employed after arthroscopy, as HO represents an exceptional complication for this kind of surgery.

$\mathrm{HO}$ within an arthroscopic hip portal was once described by Thomas-Byrd [20]. Larson [18] reported HO among the complications following his consecutive series of hip arthroscopies. The author reported incidence of 6\% (six hips), with one case of significant motion limitation resulting from ossification of the iliopsoas tendon, but no prophylaxis was mentioned.

Historically, the paucity of reports of $\mathrm{HO}$ following hip arthroscopy may be explained considering that most hip arthroscopies were performed to address labral, chondral, and synovial diseases until the last decade, when FAI gained popularity and extended the indications to include acetabular and femoral osteochondroplasties. Arthroscopic treatment of FAI may present increased risk for HO formation due to the additional manipulation of soft tissues (capsulotomy or capsulectomy). In addition, bony debris after milling might collect within periarticular soft tissues, there triggering further local bone formation.

Often arthroplasty patients complain about $\mathrm{HO}$ only if the lesion is bulky (grade 3 or 4), but hip arthroscopy patients are generally younger, more active, and motivated to return to sport activities, even at competitive levels. Since this population is definitely more demanding than usual candidates for total hip replacement, even small ossifications might affect overall satisfaction. For this reason, and on the basis of this study, we believe that prophylaxis should be considered.

To the best of our knowledge, this is the first study reporting prevalence of $\mathrm{HO}$ in a large consecutive series of arthroscopic femoroacetabular osteochondroplasties and its association with NSAID administration. Our analysis has shown a significant difference in the frequency of such complications between patients who received NSAIDs postoperatively and patients who did not.

This study presents several limitations. Its most important weakness is the small sample size of the control group. The strong asymmetry between treatment and control groups may have biased their comparison. However, given the large difference we observed, a randomized controlled trial could hardly be acceptable from an ethical point of view.

Moreover, the prophylaxis regimen is heterogeneous. Different drugs may be differently effective for HO prevention. Nevertheless, this study has the purpose of verifying the association between any NSAID prophylaxis, considered as the main independent variable, and HO. Further studies are needed to evaluate the specific effectiveness of any single medication.

Several factors are also known or supposed to be associated with increased risk for formation of heterotopic bone
[2]. Referring to hip arthroscopy, capsular incision and resection to expose the peripheral cam deformity, extensive rim trimming, anchor placement, and male gender might be the most relevant predisposing factors. Due to the relevant limitations of this study, a systematic and comprehensive analysis of these multiple risk factors was not possible.

In conclusion, arthroscopic treatment of FAI is not exempt from potential formation of HO. This study evaluated the effects of NSAIDs on HO development and observed a significantly higher complication rate in those patients who did not receive prophylaxis. Thus, the authors suggest NSAID prophylaxis after hip arthroscopy when FAI is addressed.

\section{Conflict of interest None.}

Open Access This article is distributed under the terms of the Creative Commons Attribution Noncommercial License which permits any noncommercial use, distribution, and reproduction in any medium, provided the original author(s) and source are credited.

\section{References}

1. Neal B, Gray H, MacMahon S, Dunn L (2002) Incidence of heterotopic bone formation after major hip surgery. ANZ J Surg 72:808-821

2. Ritter MA, Vaughan RB (1977) Ectopic ossification after total hip arthroplasty. Predisposing factors, frequency, and effect on results. J Bone Joint Surg Am 59:345-351

3. Riegler HF, Harris CM (1976) Heterotopic bone formation after total hip arthroplasty. Clin Orthop Relat Res 117:209-216

4. Charnley J (1972) The long term results of low friction arthroplasty of the hip performed as a primary intervention. $\mathrm{J}$ Bone Joint Surg 54B:61-76

5. Rosendahl S, Christoffersen K, Norgaard M (1973) Para-articular ossification after total hip replacement. Acta Orthop Scand 43:400

6. Schmidt SA, Kjaersgaard-Andersen P, Pedersen NW, Kristensen SS, Pedersen P, Nielsen JB (1988) The use of indomethacin to prevent the formation of heterotopic bone after total hip replacement. A randomized, double-blind clinical trial. J Bone Joint Surg Am 70:834-838

7. Pagnani MJ, Pellicci PM, Salvati EA (1991) Effect of aspirin on heterotopic ossification after total hip arthroplasty in men who have osteoarthrosis. J Bone Joint Surg Am 73:924-929

8. Romano CL, Duci D, Romano D, Mazza M, Meani E (2004) Celecoxib versus indomethacin in the prevention of heterotopic ossification after total hip arthroplasty. J Arthroplasty 19(1): $14-18$

9. Grohs JG, Schmidt M, Wanivenhaus A (2007) Selective COX-2 inhibitor versus indomethacin for the prevention of heterotopic ossification after hip replacement: a double-blind randomized trial of 100 patients with 1-year follow-up. Acta Orthop 78(1): 95-98

10. Glick JM, Sampson TG, Gordon RB, Behr JT, Schmidt E (1987) Hip arthroscopy by the lateral approach. Arthroscopy 3:4-12

11. Byrd JW (1994) Hip arthroscopy utilizing the supine position. Arthroscopy 10:275-280

12. Philippon MJ, Briggs KK, Yen YM, Kuppersmith DA (2009) Outcomes following hip arthroscopy for femoroacetabular 
impingement with associated chondrolabral dysfunction: minimum two-year follow-up. J Bone Joint Surg Br 91(1):16-23

13. Sampson TG (2008) Arthroscopic treatment of femoroacetabular impingement. Am J Orthop 37(12):608-612

14. Berndt C, Ganko A, Whitehouse SL, Crawford RW (2008) Heterotopic ossification within an arthroscopic portal after uneventful partial meniscectomy. Knee 15(5):416-418

15. Sodha S, Nagda SH, Sennett BJ (2006) Heterotopic ossification in a throwing athlete after elbow arthroscopy. Arthroscopy 22(7):802e1-802e3

16. Boynton MD, Enders TJ (1999) Severe heterotopic ossification after arthroscopic acromioplasty: a case report. J Shoulder Elbow Surg 8(5):495-497
17. Berg EE, Ciullo JV, Oglesby JW (1994) Failure of arthroscopic decompression by subacromial heterotopic ossification causing recurrent impingement. Arthroscopy 10(2):158-161

18. Larson CM, Giveans MR (2008) Arthroscopic management of femoroacetabular impingement: Early outcomes measures. Arthroscopy 24(5):540-546

19. Brooker AF, Bowerman JW, Robinson RA, Riley LH (1973) Ectopic ossification following total hip replacement. Incidence and a method of classification. J Bone Joint Surg 55A:1629-1632

20. Thomas-Byrd JW (1998) Complications associated with hip arthroscopy. In: Operative hip arthroscopy, chap 12. Thieme Medical Publisher Inc., New York, pp 171-176 